\title{
Cardiac magnetic resonance assessment of aortic distensibility in prediabetic patients
}

\author{
Nady A. Razik (D), Y. T. Kishk, Madeeha Younis Bakheet, Mina Nous and Mohamed Abdel Ghany
}

\begin{abstract}
Background: Hyperglycemia, insulin resistance, and hyperinsulinemia represent important pathophysiological components of the prediabetic stage that result in arteriosclerosis and increased arterial stiffness. We sought to compare the aortic distensibility (AD) assessed by cardiac magnetic resonance (CMR) in prediabetic patients presenting with chronic coronary artery disease (CCAD) versus patients with normal HbA1C. Ninety-eight patients with CCAD were recruited. All patients were screened for HbA1C levels and then underwent a CMR study to assess $A D$ of the aortic root and the ascending and descending thoracic aorta. Patients were classified into two groups: 52 prediabetic (HbA1C 5.7-6.4\%) (study group) and 46 with normal glycemic status (HbA1C < 5.7\%) (control group).

Results: AD values at the aortic root (AR) $\left(13.93 \pm 5.17 \mathrm{vs} 34.3 \pm 9.65 \mathrm{Kpa}^{-1} \times 10^{-3}\right)$, ascending aorta (AA) (13.17 \pm 4.81 vs $\left.28.1 \pm 8.33 \mathrm{Kpa}^{-1} \times 10^{-3}\right)$, and descending thoracic aorta (DA) $\left(18.12 \pm 4.34 \mathrm{vs} 33.68 \pm 7.57 \mathrm{Kpa}^{-1} \times 10^{-3}\right)$ were significantly lower in the study group than in the control group ( $P$ value for all was $<0.001)$. Twenty-eight patients fulfilled the criteria for metabolic syndrome, and in those patients, AD was significantly lower than in those without metabolic syndrome.

Aortic distensibility at the $A R, A A$, and DA had strong significant negative correlations with the level of glycosylated hemoglobin (AA, AR, DA; $r-0.66,-0.68,-0.58$, respectively) $(P<0.001)$.

Conclusion: $A D$ values at different points ( $A R, A A$, and $D A$ ) were significantly lower in prediabetic and metabolic syndrome patients than in controls. These values also showed a significant negative correlation with the levels of HBA1C.
\end{abstract}

Keywords: Aortic distensibility, Prediabetes, Metabolic syndrome, CMR, CAD

\section{Background}

Arterial stiffness is an early detectable manifestation of adverse structural and functional changes of the vessel wall [1].

Insulin resistance can promote arterial stiffness and plaque progression through downregulation of insulin signaling pathways and alterations in lipid metabolism; moreover, inflammatory pathways support the role of insulin resistance in the pathophysiology of aortic stiffness [2].

Increased arterial stiffness is an early phenomenon that occurs in the impaired glucose metabolic state [3]. Insulin has acute vasodilator effects that lead to increased arterial distensibility, and this beneficial effect is blunted in insulin-resistant states. Increased stiffness is a feature of insulin resistance [4].

\footnotetext{
* Correspondence: nadyabdelrazik@yahoo.com
}

Assiut University, Asyut, Egypt

Chronic hyperglycemia and hyperinsulinemia increase the local activity of the renin-angiotensin aldosterone system and expression of angiotensin type I receptor in vascular tissue, promoting the development of wall hypertrophy and fibrosis [5].

In addition, low-grade inflammation and endothelial dysfunction, which are interrelated, may also explain, at least in part, the increase in arterial stiffness related to diabetes and metabolic syndrome [6].

Greater arterial stiffness increases cardiovascular disease risk by increasing blood pressure, increasing ventricular hypertrophy, decreasing coronary perfusion, and increasing the risk of stroke [7].

Many methods have been used to assess aortic distensibility (AD), but CMR has the unique ability to provide both local and regional direct noninvasive measures of aortic function. Lumen area changes (aortic strain) over the cardiac cycle can be acquired with high temporal 
and spatial resolution, and aortic distensibility can be measured in different locations [8].

\section{Methods}

\section{Study subjects}

Ninety-eight patients were enrolled: 8 women and 90 men diagnosed with CCAD (patients with documented $\mathrm{CAD}$ and stable for 3 months) underwent CMR. The study was approved by our local ethics committee, and written consent was obtained from each patient. The patients were classified into 52 prediabetics with elevated HbA1C (defined range 5.7-6.4\%) (study group) and 46 patients with normal $\mathrm{HbA1C}$ (control group). The exclusion criteria included age $<18$ years, any contraindications to MRI, and a history of DM, HTN, renal impairment, LVEF less than 45\%, and aortic diseases (more than moderate aortic regurgitation; more than mild aortic stenosis and aortic aneurysm).

\section{Laboratory investigations}

Glycosylated hemoglobin (HbA1C) for all patients was analyzed by radioimmunoassays by COBAS INTEGRA 400 PLUS/800 analyzers (Roche, USA) through the Assiut University laboratory. Complete blood count $(\mathrm{CBC})$, serum urea and creatinine, and a lipid profile including total cholesterol (TC), triglycerides (TG), HDL-c (high-density lipoprotein cholesterol), and LDL-c (lowdensity lipoprotein cholesterol) for all patients were analyzed by Hitachi Cobas c 501 analyzers.

\section{Echocardiography}

All patients underwent echocardiography. The same operator and same device (GE Vivid S5) was used to minimize interobservational variability. LV volumes were measured using 2D echocardiography. Significant aortic regurge was excluded by color Doppler study of the aorta in the parasternal long-axis (PLAX) and apical 5chamber views. Aortic diameters were measured and included the aortic root, ascending aorta in PLAX view, arch, and descending aorta in suprasternal view.

\section{Assessment of aortic distensibility by CMR}

CMR acquisition was performed with Ingenia Philips 1.5 Tesla MRI scanner. Electrocardiogram (ECG)-gated gradient-echo phase-contrast cine sequence with velocity encoding FFE with breath-holding was taken at 2 levels: one in the axial plane at the level of the sinotubular junction for calculation of aortic root luminal diameter (by the average of the three end-diastolic cuspcommissure measurements) and another perpendicular to the descending aorta at the level of the bifurcation of the pulmonary artery for calculation of ascending and descending aorta luminal diameters, with a repetition time equal to the RR interval (in ms) and a 14-ms echo time, $256 \times 256$ matrix size, 300-mm field of view, 8$\mathrm{mm}$ slice thickness, and $20^{\circ}$ flip angle. Acquisition was performed using two views for appropriate alignment of the cut (for example, using an LVOT view and a 3chamber view for the aortic root and using a coronal view and LVOT view for the ascending aorta). Modulus images of the cine phase-contrast sequences were used to calculate the corresponding aortic section luminal diameter. Aortic contours were automatically traced throughout the cardiac cycle and then manually corrected (if needed) using QFLOW software (Phillips, the Netherlands).

The maximum and minimum ascending and descending aortic luminal areas were determined from the maximum and minimum cross-sectional areas of the corresponding aortic section, respectively, and then, we obtained a curve and generated a table (plotting the luminal area against trigger time) (Fig. 1). Using this curve, we measured the aortic distensibility of the corresponding aortic section with the following equation: $1000 \times$ (systolic aortic area $\left(\mathrm{cm}^{2}\right)-$ diastolic aortic area $\left(\mathrm{cm}^{2}\right) /\left(\right.$ diastolic aortic area $\left(\mathrm{cm}^{2}\right) \times$ pulse pressure $(\mathrm{mmHg})$ [8].Systolicaorticareacm ${ }^{2}$-Diastolicaorticar$\mathrm{eacm}^{2}$ Distolicaorticarea $\mathrm{cm}^{2} \mathrm{xPulsepressure}(\mathrm{mmHg})$

Blood pressure (BP) was measured twice at the time of the scan, and the average reading was used. Pulse pressure was calculated as the difference between systolic and diastolic BP.

\section{Results}

\section{Patient characteristics}

The mean age of the patients was $51.04 \pm 6.44$ years, and the majority of them were males $(92.3 \%)$, while the mean age of the controls was $49.30 \pm 6.31$ years, and the majority (91.3\%) of them were males. The mean body mass index was significantly higher in the patients with prediabetes $\left(30.07 \pm 4.76 \mathrm{~kg} / \mathrm{m}^{2}\right)$ than in the controls $(25.62 \pm 3.02, P<0.001)$. Additionally, the patients with prediabetes had significantly higher waist circumference than the controls $(108.5 \pm 7.13$ $\mathrm{cm}$ versus $93.70 \pm 7.70 \mathrm{~cm} ; P<0.001)$.

The patients with prediabetics had significantly higher diastolic blood pressure and pulse pressure than the controls $(P<0.001)$, but systolic blood pressure was not significantly different between the two groups $(P=0.91)$ (Table 1).

There were no significant differences between the two groups regarding aortic root diameter, aortic velocity index, left atrium diameter, and ejection fraction (Table 1).

Hemoglobin and creatinine levels were not significantly different between the two groups $(P>0.05)$. The study showed that cholesterol $(200.11 \pm 39.37$ versus 

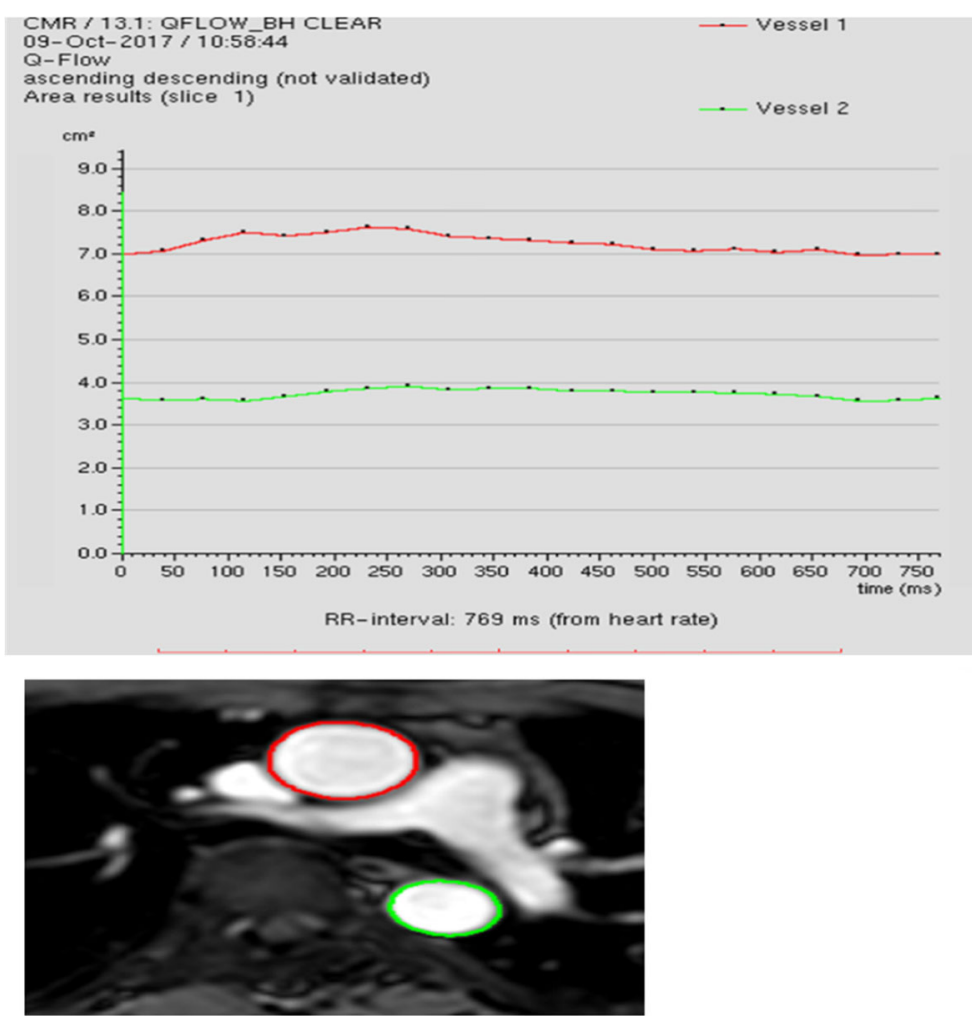

Fig. 1 Snapshot image from Philips Q flow software. TOP: chart illustrating cross-sectional area change of ascending and descending aorta at the level of pulmonary artery bifurcation during the cardiac cycle. Bottom A modulus image of Q-flow sequence of ascending and descending aorta at the level of pulmonary artery bifurcation with contouring

Table 1 Clinical characteristics of the study and control groups

\begin{tabular}{llll}
\hline Patient characteristics & Study group & Control group & $P$ value \\
\hline Age (years) & $51.04 \pm 6.44$ & $49.30 \pm 6.31$ & $<.34$ \\
BMI & $30.07 \pm 4.76$ & $25.62 \pm 3.02$ & $<.001$ \\
Waist circumference (cm) & $108.5 \pm 7.13$ & $93.70 \pm 7.70 \mathrm{~cm}$ & 0.001 \\
SBP & $118.46 \pm 5.24$ & $118.68 \pm 4.56$ & 0.91 \\
DBP & $76.92 \pm 7.35$ & $82.60 \pm 4.48$ & $<.36 .08 \pm 4.99$ \\
PP & $41.53 \pm 5.43$ & & $<0.001$ \\
Lipid profile & & $5.22 \pm 0.41$ & $<.001$ \\
Glycosylated hemoglobin (Hgb A1c) & $6.02 \pm 0.23$ & $183.20 \pm 40.30$ & 0.001 \\
Cholesterol (mg/dl) & $200.11 \pm 39.37$ & $144.13 \pm 29.88$ & 0.22 \\
Triglyceride (mg/dl) & $157.19 \pm 41.60$ & $45.80 \pm 4.69$ & $<.29$ \\
HDL (mg/dl) & $37.73 \pm 6.78$ & $99 \pm 19.17$ & $<0.001$ \\
LDL (mg/dl) & $130.80 \pm 28.40$ & & 0.001 \\
Echo parameters & & $55.80 \pm 2.04$ & $3.08 \pm 0.35$ \\
Ejection fraction (\%) & $53.23 \pm 5.07$ & $4.28 \pm 0.70$ & 0.45 \\
Aortic root (cm) & $3.16 \pm 0.41$ & $3.98 \pm 0.6$ & 0.13 \\
Left atrium (cm) & &
\end{tabular}


Table 2 Aortic distensibility in study and control groups

\begin{tabular}{|c|c|c|c|}
\hline Distensibility & Study group $(n=52)$ & Control group $(n=46)$ & $P$ value \\
\hline \multicolumn{4}{|c|}{ AR distensibility } \\
\hline $\mathrm{Kpa}^{-1} \times 10^{-3}$ & $13.93 \pm 5.17$ & $34.30 \pm 9.65$ & $<0.001$ \\
\hline \multicolumn{4}{|c|}{ AA distensibility } \\
\hline $\mathrm{Kpa}^{-1} \times 10^{-3}$ & $13.17 \pm 4.81$ & $28.10 \pm 8.33$ & $<0.001$ \\
\hline \multicolumn{4}{|c|}{ DA distensibility } \\
\hline $\mathrm{Kpa}^{-1} \times 10^{-3}$ & $18.12 \pm 4.34$ & $33.08 \pm 7.57$ & $<0.001$ \\
\hline
\end{tabular}

$183.20 \pm 40.30, P=0.22)$ and triglyceride $(157.19 \pm$ 41.60 versus $144.13 \pm 29.88, P=0.29$ ) levels were nonsignificantly higher in the study group than in the control group, while LDL levels were significantly higher in the study group than in the control group (130.80 \pm 28.40 versus $99 \pm 19.17, P<0.001$, respectively). HDL levels were significantly lower in the study group than in the control group $(37.73 \pm 6.78$ versus $45.80 \pm 4.69, P<$ 0.0001 , respectively) (Table 1 ).

\section{Aortic distensibility by CMR}

Aortic distensibility values at different points (aortic root, ascending aorta, and descending aorta) were significantly lower in the prediabetes patients than in the controls $(P<0.001)$ (Table 2$)$. Moreover, these values had a strong significant negative correlation with the level of glycosylated hemoglobin $(P<0.001)$ (Table 3$)$.

\section{Correlation between aortic distensibility and glycosylated hemoglobin}

Aortic distensibility values in different areas (aortic root, ascending aorta, and descending aorta) had strong significant negative correlations with the levels of glycosylated hemoglobin $(P<0.001)(r=66,68,58$, respectively $)$ (Table 3, Fig. 2).

\section{Relationship between aortic distensibility and age}

Aortic distensibility at the aortic root and descending aorta had no significant correlations with the age of the subjects $(P>0.05)$, but distensibility of the ascending aorta had a moderately significant correlation with age $(r$ $=-0.40, P=0.03)($ Table 3$)$.

\section{Correlation between aortic distensibility and body mass index}

Aortic distensibility in different areas (aortic root, ascending aorta, and descending aorta) had significant negative correlations with body mass index values $(P<$ 0.001) (Table 3). Moreover, aortic distensibility in different areas (aortic root, ascending aorta, and descending aorta) had significant negative correlations with waist circumference values $(P<0.001)$ (Table 3$)$.

Using multivariate regression analysis, the following were predictors for aortic stiffness in the prediabetes patients with an adjusted $R^{2}$ value of 0.59: body mass index, glycosylated $\mathrm{Hb}$, and waist circumference (Table 4).

\section{Relationship between aortic distensibility and metabolic syndrome}

Twenty-eight patients were diagnosed with metabolic syndrome ( 25 from the study group and 3 from the normal glycemic group) based on the criteria of the modified ATP III (Adult Treatment Panel III) published by the IDF (International Diabetes Federation) in 2005 [9]. Aortic distensibility values at different points (aortic root, ascending aorta, and descending aorta) were significantly lower in those patients with metabolic syndrome than in those without metabolic syndrome (AR: 13.36 vs $17.05, P<0.01$; AA: 12.48 vs $16.93, P=0.04$; DA: 18.03 vs $18.62, P=0.01$ ) (Table 5 ).

\section{Discussion}

In this study, aortic distensibility was significantly lower in the prediabetes group than in the control group. We also found a significant negative correlation between

Table 3 Correlation between aortic distensibility, $\mathrm{HbA1C}$, age, BMI, and waist circumference

\begin{tabular}{|c|c|c|c|c|c|c|}
\hline & \multicolumn{6}{|c|}{ Aortic distensibility $\left(\mathrm{kpa}^{-1} \times 10^{-3}\right)$} \\
\hline & \multicolumn{2}{|c|}{ Aortic root } & \multicolumn{2}{|c|}{ Ascending aorta } & \multicolumn{2}{|c|}{ Descending aorta } \\
\hline & $\bar{R}$ & $P$ value & $\bar{r}$ & $P$ value & $\bar{r}$ & $P$ value \\
\hline $\mathrm{HbA1C}$ & -0.66 & $<0.001$ & -0.68 & $<0.001$ & -0.58 & $<0.001$ \\
\hline Age & -0.03 & 0.83 & -0.40 & 0.03 & -0.08 & 0.56 \\
\hline BMI & -0.43 & $<0.001$ & -0.38 & $<0.001$ & -0.41 & $<0.001$ \\
\hline Waist circumference & -0.74 & $<0.001$ & -0.70 & $<0.001$ & -0.60 & $<0.001$ \\
\hline
\end{tabular}




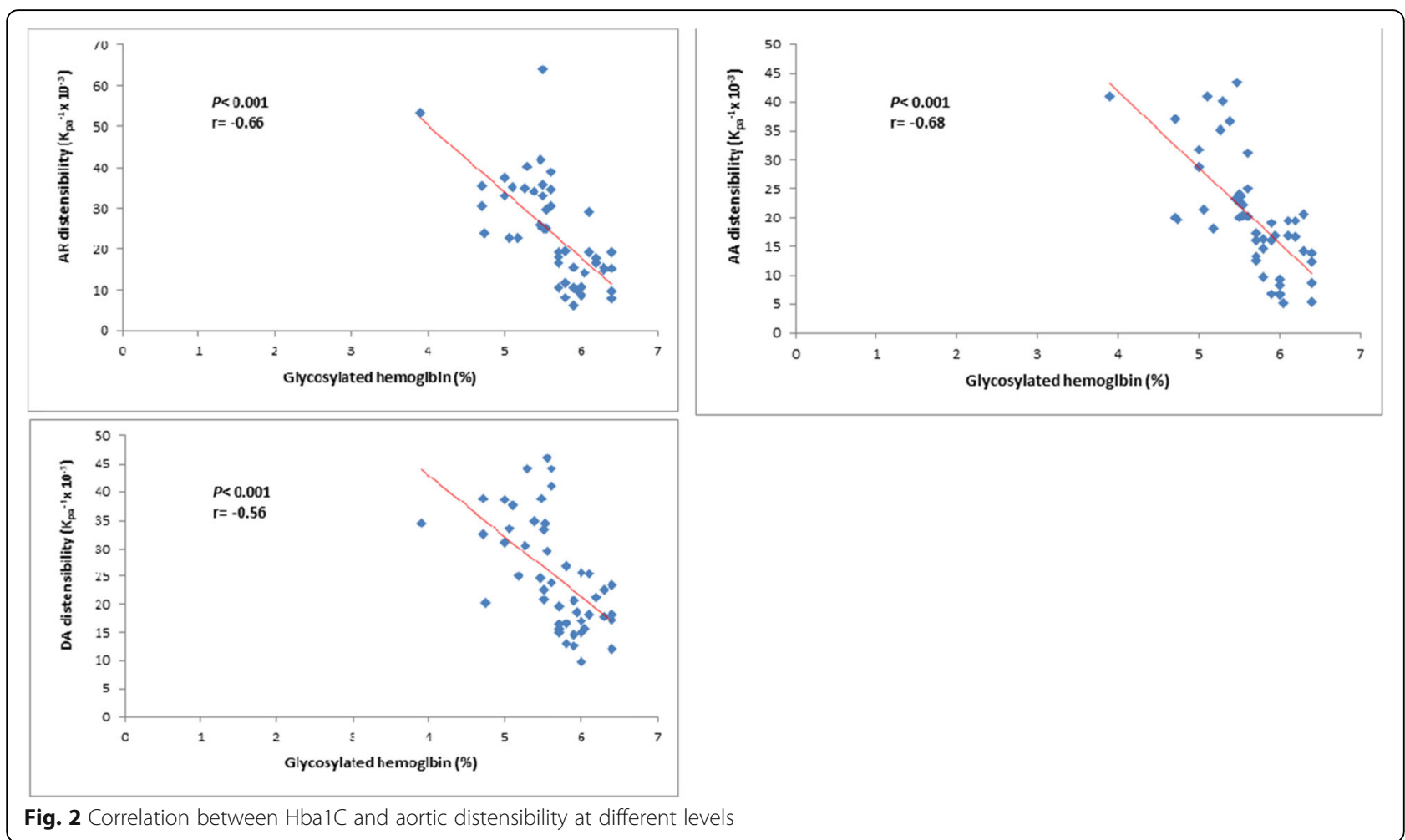

aortic distensibility and the levels of HbA1C. Impaired glucose tolerance alters the mechanical properties of the interstitial tissue of the vascular wall; moreover, it enhances nonenzymatic glycation of proteins. Nonenzymatic glycation leads to the formation of increased collagen crosslinks that result in increased arterial stiffness [10-12].

In the current study, all patients' ages were between the 3rd and 5th decades to avoid age effects on aortic elastic properties; that is, in individuals $\geq 55$ years of age, PP increased more markedly and strain continued to decline, leading to lesser sensitivity of aortic distensibility as a marker of arterial aging beyond this age [13].

The current study showed that BMI and WC were higher in the study group than in the control group. These findings are consistent with the results of Marini et al., who assessed cardiometabolic risk profiles in individuals with prediabetes [12]. In our study, there was no significant difference in systolic blood pressure (SBP) between the study and control groups; on the contrary, diastolic blood pressure (DBP) and pulse pressure were different, which was not consistent with a randomized controlled trial that assessed $\mathrm{BP}$ variability in individuals with prediabetes that showed higher SBP and DBP, which may be explained by the nonuse of ambulatory BP monitoring in our study [13].

In the current study, aortic distensibility (AD) values at different locations (aortic root, ascending aorta, and descending aorta) had significant negative correlations with waist circumference, which was consistent with another study that assessed AD in untreated essential hypertension patients, although they had measured aortic PWV with the SphygmoCor VX system for aortic stiffness assessment [14].

Our control group demonstrated AA distensibility of $28.10 \pm 8.33 \mathrm{Kpa}^{-1} \times 10^{-3}(P<0.001)$ and $\mathrm{DA}$

Table 4 Multivariate regression analysis for prediction of aortic stiffness

\begin{tabular}{llll}
\hline Variables & Odd's ratio & $95 \%$ confidence interval & $P$ value \\
\hline Body mass index & 1.45 & $1.34-3.45$ & 0.01 \\
Glycosylated $\mathrm{Hb}$ & 2.18 & $2.01-5.45$ & 0.01 \\
$\mathrm{HDL}$ & 0.45 & $0.33-1.98$ & 0.45 \\
$\mathrm{LDL}$ & 1.56 & $0.87-1.99$ & 0.29 \\
Waist circumference & 1.22 & $1.11-2.10$ & 0.01 \\
\hline
\end{tabular}


Table 5 Aortic distensibility in studied patients based on the presence of the metabolic syndrome

\begin{tabular}{|c|c|c|c|}
\hline & With metabolic syndrome & Without metabolic syndrome & $P$ value \\
\hline \multicolumn{4}{|c|}{$\overline{\text { AR distensibility }}$} \\
\hline $\mathrm{Kpa}^{-1} \times 10^{-3}$ & $13.36 \pm 5.38$ & $17.05 \pm 2.31$ & 0.01 \\
\hline \multicolumn{4}{|c|}{ AA distensibility } \\
\hline $\mathrm{Kpa}^{-1} \times 10^{-3}$ & $12.48 \pm 4.83$ & $16.93 \pm 2.66$ & 0.04 \\
\hline \multicolumn{4}{|c|}{ DA distensibility } \\
\hline $\mathrm{Kpa}^{-1} \times 10^{-3}$ & $18.03 \pm 4.59$ & $18.62 \pm 2.97$ & 0.01 \\
\hline
\end{tabular}

distensibility of $33.08 \pm 7.57 \mathrm{Kpa}^{-1} \times 10^{-3}(P<0.001)$, which is consistent with the values reported by Redheuil et al. in a cross-sectional randomized controlled trial that assessed distensibility by MRI $\left(21.3 \pm 2 \mathrm{Kpa}^{-1} \times\right.$ $\left.10^{-3,} P<0.0001\right)$ [8].

In our study, aortic distensibility at the aortic root and descending aorta was not significantly correlated with the age of the subjects, AR $(r=-0.03, P<0.83)$, and DA $(r=-0.08, P<0.56)$; however, the distensibility of the ascending aorta had a moderate significant correlation with age, which may be attributed to the higher elastin content of the ascending aorta that may decrease with age [15].

Our results were also consistent with the MESA study that used fasting glucose levels to diagnose glucose intolerance and its effect on proximal thoracic aortic distensibility by MRI, which found that glucose status had no effect on AD in subjects aged > 65 years old, while aortic distensibility values in the age-matched subgroup were similar to our results $\left(2.11 \times 10^{-3} \mathrm{mmHg}^{-1}\right.$ for IFG, $P=0.01)$ [15].

The present study showed that patients with metabolic syndrome have lower $\mathrm{AD}$ and that waist circumference, $\mathrm{BMI}$, and $\mathrm{HbA} 1 \mathrm{C}$ were stronger predictors of worse AD. Metabolic syndrome increases the risk of CV disease in many ways and increases arterial stiffness in all ages [16-18]. The sympathetic nervous system, reninangiotensin system, inflammatory cytokines, and hyperdynamic circulation play an important pathophysiologic role in metabolic syndrome [19].

Aortic elasticity indices have been linked to the occurrence of CV events and target organ damage in prediabetics, diabetics, and hypertensives, which emphasizes the importance of assessing aortic distensibility (as one of aortic elasticity markers) in these patients [20, 21].

\section{Conclusions}

Individuals with prediabetes and those with metabolic syndrome have worse aortic elastic properties than those with normal glycemic index values. CMR provides a relatively easy and reproducible method for the assessment of local aortic function in comparison to the cumbersome old methods with commonly encountered limitations and pitfalls [22].

\section{Abbreviations \\ AA: Ascending aorta; AD: Aortic distensibility; AR: Aortic root; ATP III: Adult treatment panel III; BMI: Body mass index; CBC: Complete blood count; CCAD: Chronic coronary artery disease; CMR: Cardiac magnetic resonance; CV: Cardiovascular; DA: Descending aorta; DBP: Diastolic blood pressure; DM: Diabetes mellitus; ECG: Electrocardiogram; HbA1C: Glycosylated hemoglobin; HDL: High-density lipoproteins; HTN: Hypertension; IDF: International Diabetes Federation; IFG: Impaired fasting glucose; LDL- c: Low-density lipoprotein cholesterol; LV: Left ventricle; LVEF: Left ventricle ejection fraction; MESA study: Multi-ethnic study of atherosclerosis; MRI: Magnetic resonance imaging; PLAX: Parasternal long axis; SBP: Systolic blood pressure; TC: Total cholesterol; TG: Triglycerides; WC: Waist circumference}

\section{Acknowledgements \\ Not applicable}

\section{Authors' contributions}

NA contributed to the conception, design of the work, acquisition, analysis, and interpretation of data and drafted the work or substantively revised it, approved the submitted version, agreed both to be personally accountable for the author's own contributions and to ensure that questions related to the accuracy or integrity of any part of the work. YT contributed to the conception, design of the work, and interpretation of data and approved the submitted version. MY contributed to the design of the work, acquisition, analysis, and interpretation of data. MN contributed to the acquisition, analysis, and interpretation of data and drafted the work or substantively revised it. MA contributed to the conception, design of the work, analysis, and interpretation of data and drafted the work or substantively revised it, approved the submitted version, and agreed both to be personally accountable for the author's own contributions and to ensure that that questions related to the accuracy or integrity of any part of the work. All authors have read and approved the final manuscript.

\section{Funding}

No funding received for this study.

\section{Availability of data and materials}

Data including excel sheets, and MRI results are available

\section{Ethics approval and consent to participate}

The study was approved by our local ethics committee (No. 17100819, Faculty of Medicine, Assiut University), and written consent was taken from each subject.

\section{Consent for publication \\ Not applicable}

\section{Competing interests}

The authors declare that they have no competing interests. 
Received: 7 October 2019 Accepted: 12 January 2020

Published online: 21 January 2020

\section{References}

1. Izzo JJ (2004) Arterial stiffness and the systolic hypertension syndrome. Curr Opin Cardiol 19(4):341-352

2. Laakso M, Kuusisto J (2014) Insulin resistance and hyperglycemia in cardiovascular disease development. Nat Rev Endocrinol 10:293

3. Henry RM, Kostense PJ, Spijkerman AM et al (2003) Arterial stiffness increases with deteriorating glucose tolerance status: the Hoorn Study. Circulation 107:2089-2095

4. Yki-Jarvinen H, Westerbacka J (2007) Insulin resistance, arterial stiffness, and wave reflection. Adv Cardiol 44:252-260

5. Creager MA, Luscher TF, Cosentino F, Beckman JA (2003) Diabetes and vascular disease: pathophysiology, clinical consequences, and medical therapy: part I. Circulation 108:1527-1532

6. Tomiyama $\mathrm{H}$, Hashimoto $\mathrm{H}$, Hirayama $\mathrm{Y}$ et al (2006) Synergistic acceleration of arterial stiffening in the presence of raised blood pressure and raised plasma glucose. Hypertension 47:180-188

7. Safar ME, Thomas F, Blacher J et al (2006) Metabolic syndrome and agerelated progression of aortic stiffness. J Am Coll Cardiol 47:72-75

8. Redheuil A, Yu WC, Wu CO et al (2010) Reduced ascending aortic strain and distensibility: earliest manifestations of vascular aging in humans. Hypertension. 55(2):319-326

9. International Diabetes Federation. Worldwide definition of metabolic syndrome. Available at: http://www.idf.org/webdata/docs/IDF_ Metasyndrome_definition.pdf. Accessed 24 Aug 2005.

10. Gerstein HC, Mann JFE, Yi Q et al (2001) Albuminuria and risk of cardiovascular events, death, and heart failure in diabetic and non-diabetic individual. JAMA 286:421-426

11. Fantin F, Mattocks A, Bulpitt CJ, Banya W, Rajkumar C (2007) Is augmentation index a good measure of vascular stiffness in the elderly? Age Ageing 36:43-48

12. Marini MA, Elena Succurro M, Ersilia Castaldo M, Giorgio Sesti M (2012) Cardiometabolic Risk Profiles and Carotid Atherosclerosis in Individuals, pp 1-6

13. Gupta AK, Greenway FL, Cornelissen G, Pan W, Halberg F (2008) Prediabetes is associated with abnormal circadian blood pressure variability. J Hum Hypertens 22:627

14. Schillaci G, Pirro M, Vaudo G, Mannarino MR, Savarese G, Pucci G, Mannarino E (2005) Metabolic syndrome is associated with aortic stiffness in untreated essential hypertension, pp 1078-1082

15. Stacey RB, Bertoni AG, Eng J, Bluemke DA, Hundley WG, Herrington D (2009) Epidemiology/population science modification of the effect of glycemic status on aortic distensibility by age in the multi-ethnic study of atherosclerosis, pp 26-32

16. Isomaa B, Almgren P, Tuomi T, Forsén B, Lahti K, Nissén M et al (2001) Cardiovascular morbidity and mortality associated with the metabolic syndrome. Diabetes Care 24:683-689

17. Li S, Chen W, Srinivasan SR, Berenson GS (2005) Influence of metabolic syndrome on arterial stiffness and its age-related change in young adults: the Bogalusa Heart Study. Atherosclerosis 180:349-354

18. Landsberg L (2001) Insulin-mediated sympathetic stimulation: role in the pathogenesis of obesity-related hypertension (or, how insulin affects blood pressure, and why). J Hypertens 19:523-528 14

19. Wilkinson IB, Qasem A, McEniery CM, Webb DJ, Avolio AP, Cockcroft JR (2002) Nitric oxide regulates local arterial distensibility in vivo. Circulation 105:213-217

20. Garcia-Carretero R, Vigil-Medina L, Barquero-Perez O, Ramos-Lopez J (2019) Pulse wave velocity and machine learning to predict cardiovascular outcomes in prediabetic and diabetic populations. J Med Syst. 44:019-1479

21. Vasan RS, Short MI, Niiranen TJ, Xanthakis V, DeCarli C, Cheng S, Seshadri S, Mitchell GF (2019) Interrelations between arterial stiffness, target organ damage, and cardiovascular disease outcomes. J Am Heart Assoc. 8: e012141-e012141

22. Goudot G, Mirault T, Bruneval P, Soula G, Pernot M, Messas E (2019) Aortic wall elastic properties in case of bicuspid aortic valve. Front Physiol. 10:299

\section{Publisher's Note}

Springer Nature remains neutral with regard to jurisdictional claims in published maps and institutional affiliations.

\section{Submit your manuscript to a SpringerOpen ${ }^{\circ}$ journal and benefit from:}

- Convenient online submission

- Rigorous peer review

- Open access: articles freely available online

High visibility within the field

- Retaining the copyright to your article

Submit your next manuscript at $\boldsymbol{\nabla}$ springeropen.com 